\title{
Perceptions of community health workers on their training, teamwork and practice: a cross-sectional study in Tshwane district, Gauteng, South Africa.
}

\author{
SLN Nyalunga*, JV Ndimande, GA Ogunbanjo $\mathbb{D}$, A Masango-Makgobela and T Bogongo \\ Discipline of Family Medicine, Sefako Makgatho Health Sciences University, Pretoria, South Africa \\ *Corresponding author, email: snnyalunga@gmail.com
}

Background: In 2011, South Africa established ward-based outreach teams (WBOTs) comprising Community Health Workers as part of strategies to strengthen primary healthcare. The new community health workers (CHWs) lacked experience of the programme. This study aimed at assessing perceptions of community health workers on their training, teamwork and practice. Methods: This was a cross-sectional study conducted among CHWs in the seven regions of Tshwane health district between October and November 2015. Data were collected from 431 CHWs in eight Community Health Centres and 11 clinics using a pre-tested, self-administered questionnaire. Outcome measures were CHWs' perceptions on training, teamwork and practice regarding WBOT programme.

Results: A total of $431 \mathrm{CHWs}$ formed the study sample. Participants had a mean age of 36 years (SD \pm 9.46$)$. The majority (88.2\%) were female. Some $77 \%$ had completed secondary school. Overall, most CHWs perceived their training (86.4\%), teamwork $(87.6 \%)$ and practices $(67.7 \%)$ to be good $(p=0.001)$. The majority were able to provide efficient health care despite the challenges experienced, which were lack of equipment, walking long distances, and safety on the streets and in households with patients who had mental health problems among others. Fisher's exact test showed a significant association between training and work challenges $(p=0.006)$.

Conclusion: The study findings showed that most $\mathrm{CHWs}$ had good perceptions regarding their training, teamwork and practice. Several concerns raised by CHWs suggest the need for stakeholders to ensure availability of resources for optimal functioning of CHWs.

Keywords: community health workers, training, teamwork, practice, primary health care

\section{Background}

The International Labour Organization defines Community Health Workers (CHWs) as 'members that provide support and assistance to communities, families and individuals with preventive health measures and gaining access to appropriate curative health and social services. They create a bridge between providers of health, social and community services and communities that may have difficulty in accessing these services.' ${ }^{1}$ Training increases the capacity for CHWs to communicate with and serve local people. The Brazilian Health Ministry started the implementation of a CHW model-the-family health strategy in 1988. In 2004, a specialised training programme for CHWs which is offered for eight weeks followed by four weeks' fieldwork and ongoing training sessions was developed. Since the inception of the CHW model, there have been significant reductions in infant mortality and hospitalisations due to primary care sensitive conditions. ${ }^{2}$ Government support through supplying resources for activities and through the remuneration of CHWs, such as seen in Brazil, are stated as aspects of a successful CHW programme. ${ }^{2}$

CHWs play a central role in communities despite their lack of formal training to adequately perform their activities. ${ }^{2}$ Evidence from other countries such as China and India also suggest that provision of home and community-based health services and their links with the fixed primary health care $(\mathrm{PHC})$ facilities in particular are critical to good health outcomes, especially child health outcomes. ${ }^{3,4}$ The success of $\mathrm{CHWs}^{\prime}$ programmes can be attributed to a number of factors described in the literature. ${ }^{5-7}$ Programmes have been successful when $\mathrm{CHWs}$ have been equipped with the necessary resources to conduct activities within the household, have regular training courses, ${ }^{5}$ and are monitored regularly by supervisors conducting meetings to check their activities. ${ }^{6,7}$ As seen in countries such as Rwanda, Afghanistan, Nigeria, India and Nepal, regular supervision of CHW' activities and provision of support with refresher training courses by programme supervisors are attributed with their success. $^{6,8}$

In 2011, South Africa had approximately 72000 CHWs according to an audit report by the National Department of Health. ${ }^{9}$ However, patient health outcomes were assessed to be suboptimal, especially in the areas of maternal and child health. The reasons cited included a number of factors related to the $\mathrm{CHWs}$, which are inadequate training; inadequate support and supervision; random distribution with poor coverage; no link between the community-based services and services offered by fixed health facilities; funding being channelled through non-governmental organisations (NGOs) with inadequate accountability; and limited or no targets for either coverage or quality to be reached..$^{9-11}$ It was concluded that many of these factors could be corrected if CHWs were part of a team, well trained, supported and supervised. ${ }^{9}$

South Africa established ward-based outreach teams (WBOTs) as part of strategies to strengthen primary health care in $2011 .^{12}$ In order to take health services to the communities, the national policy has outlined that communities should at least have one PHC outreach team comprising a professional nurse and 2040 community health workers. ${ }^{13,14}$ Each community health worker is assigned about 200-250 households and they are offered $59-69$ days' training. ${ }^{14,15}$ Their role as a team is to 
promote health, prevent disease and enable early detection of disease, treatment support, rehabilitation and palliation. ${ }^{15}$

In 2014, Tshwane District (GDOH) and the City of Tshwane outreach programmes were integrated to expand delivery and support of healthcare services already provided by Community Oriented Primary Care (COPC) to all active wards in the Tshwane District. COPC is also referred to as municipal wardbased primary health care. Delivery of this healthcare service was through CHWs who delivered existing programmes such as home-based care. ${ }^{16}$ Training for CHWs involved two 10-day courses: Phase I (initiated in 2012) and Phase II (initiated in 2014). In 2015, the majority (80\%) of CHWs had completed Phase I. ${ }^{16,17}$ New community CHWs with lack of experience of the programme were introduced to the WBOT services. This study aimed at assessing perceptions of $\mathrm{CHWs}$ on their training, teamwork and practice, part of an evaluation of Ward-Based Outreach Teams' three years of implementation of an NHI pilot project in Tshwane district.

\section{Methods}

\section{Study setting}

Tshwane district had a population of 3089314 according to the revised data extracted from STATS SA 2014 mid-year estimates. ${ }^{18}$ Service delivery platforms included 62 clinics, $8 \mathrm{CHCs}$, 4 satellite clinics, 8 mobile clinics and 9 health posts. There are four district hospitals that provide curative care including primary health care through a well-defined referral system. The health facilities included in this study were the 8 Community Health Centres (Kgabo, Soshanguve, Themba, Suurman, Stanza, Mamelodi, Ekangala and Dark City) and 11 clinics (Boekenhout, Kekana Gardens, Folang, Pretoria North, Bophelong, Olivenhoutbosch, Mooiplaas mobile clinic, Refilwe, Onverwaagt, Kameeldrift and Nelmapius) from within the seven sub-districts of Tshwane. Eleven clinics with functional WBOTs were randomly selected. The list of these health facilities was provided by the WBOT champion in Tshwane district.

\section{Study design}

This was a cross-sectional study conducted among CHWs in the seven sub-districts of Tshwane.

\section{Study population and sampling procedure}

At the time of the study, there were 105 wards in Tshwane District and only 68 wards were covered by active WBOTs. ${ }^{16}$ An estimation of a total population of $1600 \mathrm{CHWs}$ in Tshwane Health District was made. For a $95 \%$ confidence level, an accuracy of $\pm 5 \%$ and an assumed $70 \%$ positive response rate, the required sample size obtained was 317. A total of $431 \mathrm{CHWs}$ formed the study sample due to oversampling. A sufficiently large sample size is more representative of the population. All were aged 18 years and above, selected conveniently, based on their availability, willingness to participate and the experience of at least six months in the job.

\section{Data collection}

Data were collected using a self-administered, structured questionnaire with both closed and open-ended questions. The questionnaire was designed based on evidence from the literature. $^{19-21}$ The English questionnaire was translated into two main languages (Setswana and IsiZulu) using the method of back-translation by the researcher who is proficient in these languages. The questionnaire had four sections: baseline characteristics; questions related to $\mathrm{CHWs}^{\prime}$ training; teamwork; and practice regarding the WBOT programme. Participants were required to respond 'Yes' or 'No' to all questions asked. They were asked to support their response if it was 'No' for adequate training received and 'Yes' for a question on work challenges. It was piloted on a small sample of $20 \mathrm{CHWs}$ who did not form part of the study sample to ensure validity. Fifteen unemployed field workers were recruited to collect data. They were trained on a revised questionnaire. A field test was done on another small sample of 10 with field workers supervised by the research team before the actual data were collected. Data were collected from 15 October to 3 November 2015. One of the researchers accompanied the field workers to the study sites to assist in addressing questions raised by the participants. All CHWs convened in a central place and the field workers explained the study, invited them to participate, and obtained informed consent from those who were willing to participate in the study before they were given questionnaires to complete. The majority of CHWs completed the English version. Questionnaires were checked by the researcher for completeness and correctness when they were submitted by the field workers.

\section{Data analysis}

Data were captured in a Microsoft Excel ${ }^{\circledast}$ spreadsheet (Microsoft Corp, Redmond, WA, USA) and imported into the SAS $9.2^{\circledR}$ software package (SAS Institute, Cary, NC, USA) for analysis by a statistician. Outcome measures were $\mathrm{CHWs}^{\prime}$ perceptions on training, teamwork and practice regarding the WBOT programme. Descriptive and inferential analyses were undertaken. For overall training, teamwork and practice percentages in Table 5 , all 'Yes' and 'No' responses to questions in Tables 2, 3 and 4 were combined separately and the Z-test was performed to test whether Yes/No percentages differed from a 50:50 ratio. Fisher's exact test was used to assess association between variables (work challenges versus training). $P$-values of $\leq 0.05$ were considered significant. Frequency distribution tables were used to present analysis of variables.

\section{Ethical considerations}

All participants signed the informed consent form prior to their participation in this study and were aware of their right to withdraw at any time. Confidentiality and anonymity of data were maintained throughout and after the study. Ethical clearance for the study was received from Sefako Makgatho University Research Ethics Committee (SMUREC clearance number: SMUREC/114/2015: IR). The Tshwane District Research Committee provided permission to conduct the study in the selected district health facilities (TRC Project number: 43/2015). In addition, permission to conduct the study at the various sites was obtained from the facility managers telephonically before each site was visited.

\section{Results}

The study sample comprised $431 \mathrm{CHWs}$. For age, data were available for 425 participants, with the mean age of 36 years $( \pm 9.46)$, and range between 21 and 66 years. Thirty-six per cent were in the age group $31-40$ years. The majority $(380 / 431 ; 88.2 \%)$ were female. Of the 426 participants who responded regarding their marital status, $69.3 \%$ were single. Among the 426 participants who indicated their highest level of education, $328(77.0 \%)$ had completed secondary level of education (grades 8-12) (Table 1).

The majority (93.0\%) of participants received training on WBOT and $90.4 \%$ used the manuals as their source of reference; $85.8 \%$ were confident to perform their work. Three-quarters $(76.3 \%)$ felt that they had received adequate training and $23.7 \%$ did not. 
Table 1: CHWs' baseline characteristics

\begin{tabular}{lcc}
\hline Variables & Categories & $\begin{array}{c}\text { Frequencies and } \\
\text { percentages }\end{array}$ \\
\hline Age $(n=425)$ & $21-30$ & $129(30.4)$ \\
& $31-40$ & $153(36.0)$ \\
& $41-50$ & $103(24.2)$ \\
& $51-60$ & $38(8.9)$ \\
Sex $(n=431)$ & $>60$ & $2(0.5)$ \\
& Female & $380(88.2)$ \\
Marital status $(n=426)$ & Male & $51(11.8)$ \\
& Single & $295(69.3)$ \\
& Married & $116(27.2)$ \\
Highest level of education & Divorced & $9(2.1)$ \\
attained $(n=426)$ & Pidowed & $6(1.4)$ \\
& Secondary & $328(77.2)$ \\
& Tertiary & $87(20.4)$ \\
\hline
\end{tabular}

Recorded responses for inadequate training were: short duration of training (43/102; 42.2\%), lack of onsite demonstration of skills such as first aid, and counselling for HIV testing among others (21/102; 20.5\%) (Table 2).

The majority (91.4\%) of participants had good relationships with team members, good support (87.2\%) from the team leader and high level of trust $(89.1 \%)$ from the households. Of the 426 participants, $352(82.6 \%)$ indicated that households took responsibility for their own health (Table 3 ).

The majority of participants offered follow-up visits and support to their patients with health problems including adherence to treatment (98.8\%). They provided information and education to households and communities (98.6\%) and efficient health care $(88.2 \%)$ to households. However, $83 \%$ did not have adequate resource materials to perform their duties; they walked long distances to households (76.3\%); and did not feel safe to walk on the streets or to interview patients with mental health problems (64.7 and $64.8 \%$ respectively) (Table 4).

The CHWs who responded 'Yes' to a question on work challenges experienced were requested to give reasons or explain.
In addition to perceived obstacles already noted in Table 4, the following responses were also recorded: households not willing to register and refusing to allow unidentified CHWs (no uniform and name tags) into their premises (92/350; 26.2\%); lack of transport and medication (57/350; 16.3\%); CHWs felt that they are being overworked and are receiving inadequate stipends (38/350; 10.9\%). These are a few among other challenges recorded (see Table 4).

Of $1718 \mathrm{CHWs}^{\prime}$ combined responses to the four questions in Table 2, 86.4\% reflected positively (Yes) on training, while $13.6 \%$ did not (No). From the Z-test (Table 5), the resultant $86.4 \%$ was significantly greater $(p<0.001)$ than a chance outcome of $50 \%$. Similar calculations were done for teamwork and practice (see Tables 3 and 4).

Fisher's exact test was performed to assess the correlation between work challenges and training. The percentage of trained CWHs who found their work challenging (83.0\%) differs significantly from the percentage of untrained $\mathrm{CWHs}$ who found their work challenging $(60.0 \%)$. Likewise, the two complementary percentages ( $17.0 \%$ vs. $40.0 \%)$ also differ significantly $(p=0.006)$ (Table 6).

\section{Discussion}

The findings of the study showed that slightly over a third (36\%) of $\mathrm{CHWs}$ were between the ages of 31-40 years with a mean age of 36 years. The majority (88.2\%) were female. Some $77 \%$ of CHWs completed secondary level of education (grades 8-12) compared with $20.4 \%$ with a tertiary degree. These are nearly similar to the audit findings on WBOT services in the NorthWest province of South Africa, which showed that a proportion (32\%) of the CHWs were between the age group of 31-40 years and the median age was 37 years. The majority of these CHWs (75\%) had passed grades $8-12 .^{19}$ The $\mathrm{CHWs}^{\prime}$ age and level of education in our study imply a greater level of responsibility and career pathing. With the majority of participants being female, it is assumed that good support of the programme is achieved. Contextual factors can interact to shape $\mathrm{CHWs}^{\prime}$ performance and affect the effectiveness of the programme. ${ }^{22} \mathrm{~A}$ study by Akintola and Chikoko in Durban found that promotion to supervisory position was cited as one of the factors that motivated $\mathrm{CHWs}$ who started as unpaid volunteers and acquired experience on the job. ${ }^{23}$ The sex of CHWs has been shown to

Table 2: Training of CHWs on WBOT services

\begin{tabular}{llr}
\hline Questions & Yes (\%) & No (\%) \\
\hline Did you receive training on WBOT to clarify your roles and responsibilities? $(n=430)$ & $400(93.0)$ & $30(7.0)$ \\
\hline Were you given a manual on WBOT guidelines as your reference source? $(n=428)$ & $387(90.4)$ & $41(9.6)$ \\
\hline Are you confident with the work you are doing after training? If no, explain ......... $(n=430)$ & $369(85.8)$ & $61(14.2)$ \\
\hline Do you feel you have received adequate training regarding WBOT? If no, explain $\ldots \ldots . .(n=430)$ & $328(76.3)$ & $102(23.7)$ \\
\hline Total $(n=1718)$ & $1484(86.4)$ & $234(13.6)$ \\
\hline
\end{tabular}

Table 3: Teamwork among members

\begin{tabular}{|c|c|c|}
\hline Questions & Yes (\%) & No (\%) \\
\hline Do you have a good relationship with your team members? If no, why ...... $(n=431)$ & $394(91.4)$ & $37(8.6)$ \\
\hline Is your team leader supportive on a work and personal basis? If no, explain ...... $(n=431)$ & $376(87.2)$ & $55(12.8)$ \\
\hline Do you think the households trust you with their illnesses? If no, explain ...... $(n=431)$ & $384(89.1)$ & $47(10.9)$ \\
\hline $\begin{array}{l}\text { Do households take responsibility for and become active partners in their own health? } \\
\text { If no, explain } \ldots \ldots \ldots \ldots \ldots \ldots \ldots \ldots \ldots \ldots \ldots \ldots \ldots \ldots \ldots \ldots \ldots \ldots \ldots \ldots \ldots \ldots \ldots \ldots \\
(n=426)\end{array}$ & $352(82.6)$ & $74(17.4)$ \\
\hline Total $(n=1719)$ & $1506(87.6)$ & $213(12.4)$ \\
\hline
\end{tabular}


Table 4: CHWs' practice regarding WBOT services

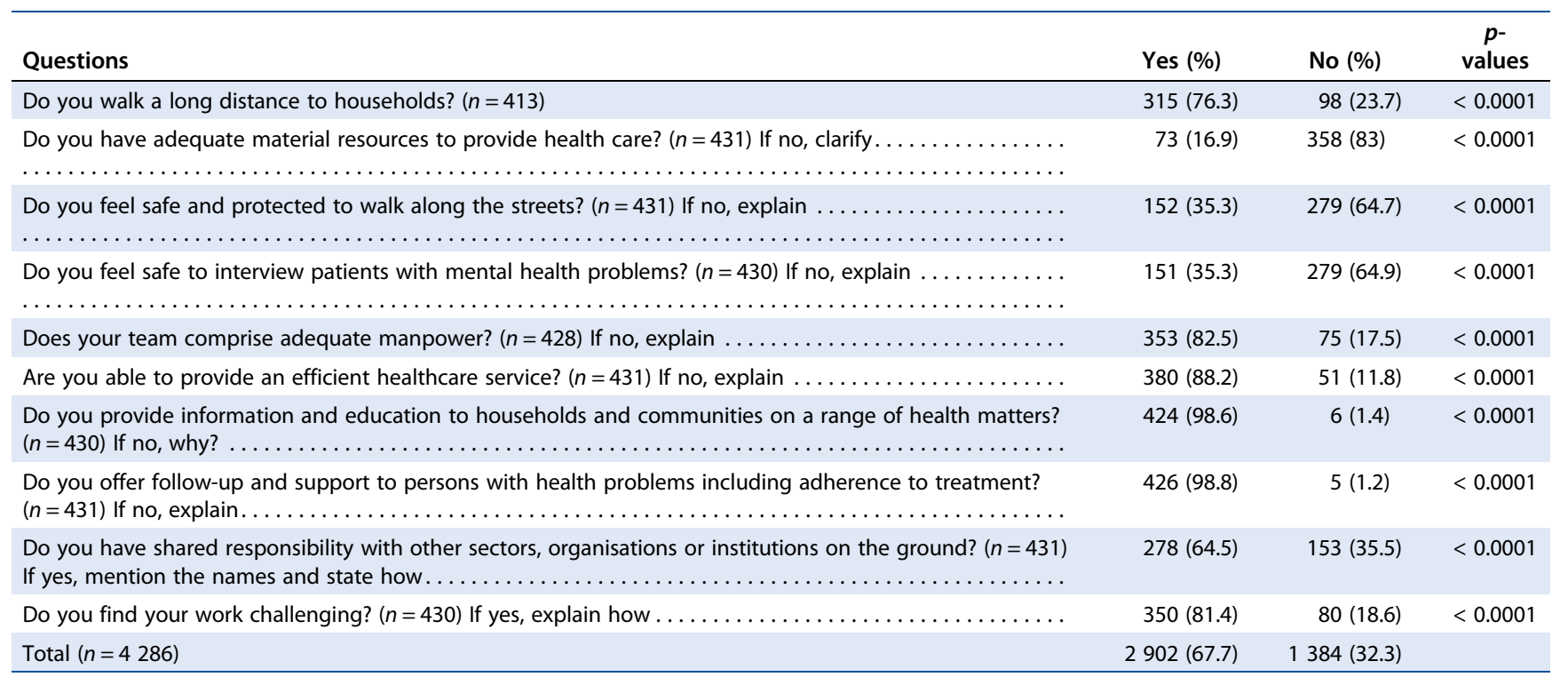

influence uptake of services in different contexts; for example in Afghanistan, Viswanathan et al. (2012) reported preference for female CHWs for delivery of maternal health services (use of modern contraceptives, skilled antenatal care and skilled birth attendance) compared with males. ${ }^{24}$ However, a study by Razee et al. (2012) in Papua New Guinea reported that a perceived lack of safety among female CHWs affected motivation to work and resulted in some resigning. ${ }^{25}$

In this study, the majority (93\%) of CHWs had received training; $76.3 \%$ perceived that the training was adequate and $85.8 \%$ were confident in performing their duties. We know that training of CHWs is one of the key aspects that seeks to develop new knowledge and skills related to specific tasks. However, a small proportion (23.7\%) of CHWs felt that the training received was inadequate and reported it to be due to a short duration of training and lack of onsite skills training. Several programmes from the literature recommend that in addition to classroom-based or health-facility in-service training, training should also take place in the community to provide hands-on experience in the work environment, and competency in performing skills should be assessed by supervisors during their visits. Continued refresher training was also cited as being as important as initial training. ${ }^{2,5-8,26}$

$\mathrm{CHWs}^{\prime}$ teamwork relationship in this study was perceived to be excellent, as reflected by a high proportion of positive responses to questions regarding relationships among the team members, support from the team leader and the trust households have in them regarding confidential matters. These responses concur with the findings of the study done in Gauteng, Sedibeng district, which showed some benefits such as having dedicated and supportive nurses in the programme, and community

Table 5: Overall training, teamwork and practice

\begin{tabular}{lcccc}
\hline Overall & $\mathbf{n}$ & Yes $\%$ & No $\%$ & $p$-value \\
\hline Training & 1,718 & 86.4 & 13.6 & $p<0.001^{* *}$ \\
Teamwork & 1,719 & 87.6 & 12.4 & $p<0.001^{* *}$ \\
Practices & 4,286 & 67.7 & 32.3 & $p<0.001^{* *}$ \\
\hline
\end{tabular}

Z-Test; ${ }^{* *} p<0.01$, highly significant. members trusting the close and immediate service they receive from the WBOTs. ${ }^{21}$ Contrary to our study findings, lack of confidentiality and trust was expressed as a major barrier to CHW acceptability in delivering health services as reported in the study by Grant et al. (2017) which was conducted in five rural districts in KwaZulu-Natal. ${ }^{27}$ The reasons were cited as lack of professionalism, familiarity and complex relationships between household members and CHWs, particularly in high HIV-prevalence settings, and professional staff at the clinics questioning $\mathrm{CHWs}^{\prime}$ competence and trustworthiness openly. ${ }^{27}$ The authors in our study are of the opinion that the differences in the setting (Tshwane being mostly urban and KwaZulu-Natal rural and with a high HIV prevalence), good teamwork and efficiency in provision of services by CHWs could have enhanced trust and support from the communities and team leaders in Tshwane District. Good teamwork and trust of CHWs enhance great interaction and influence acceptance of the programme within the communities. ${ }^{27}$

The study has shown that the majority (88.2\%) of CHWs reported that they provided an efficient healthcare service even though there were challenges such as lack of materials/equipment, medication and transport; uniforms and name tags; walking long distances; safety on the streets as they visit households and encounter patients with mental health problems; and work overload with inadequate stipend. This is consistent with the study findings in marginalised areas of Durban where supervisors and $\mathrm{CHWs}$ were found to be motivated to work even though there were dissatisfiers including working in crime-prevalent communities, ${ }^{23}$ remuneration for $\mathrm{CHWs}$, problems with material and logistical resources, and job insecurity. ${ }^{21,23}$ A study conducted by Austin-Evelyn et al. (2017) in the Eastern Cape also

Table 6: Work challenges vs. training

\begin{tabular}{lcccc}
\hline \multirow{2}{*}{ Challenges: } & \multicolumn{3}{c}{ Training } & p-value \\
\cline { 2 - 4 } & Yes (\%) & No (\%) & Total & \\
\hline Yes & $331(83.0)$ & $18(60.0)$ & 349 & $p=0.006^{* *}$ \\
No & $68(17.0)$ & $12(40.0)$ & 80 & \\
Total & 399 & 30 & 429 & \\
\hline
\end{tabular}

Fisher's exact test; ${ }^{* *} p<0.01$, highly significant; \# missing $=1$. 
found that $\mathrm{CHW}$ s experienced challenges such as a lack of equipment, uniforms and name tags, and transportation among other challenges, although these were perceived as barriers to provision of adequate quality of service. ${ }^{26}$ Similarly, Seutloali et al. also found that CHW in Lesotho were demotivated to carry out their work because of lack of or inconsistent financial incentives and supplies, work overload that compromised quality of their work and limited community involvement. ${ }^{28}$

Rapid assessment of COPC/WBOT implementation in Tshwane District in a survey by Kinkel et al. identified challenges such as: relationship between government and NGOs concerning the conditions of service of employment of CHWs; relationship between service providers and the people they serve; and CHWs' security when they have to enter peoples' homes, which is in keeping with our study findings. ${ }^{15}$ We were recently made aware that the Tshwane District Health Department is providing CHWs with uniforms, hand-held devices for data collection and kit bags containing blood pressure machines, glucometers, gloves, dressing packs and others. These resources are shared among $\mathrm{CHWs}$, since not everyone received the items. However, stipend, transport and safety still remain a challenge. If these challenges are not addressed over time, this may lead to CHWs being demotivated and seeking jobs elsewhere, thus leading to a high dropout rate. According to Haines et al. (2012), a high attrition rate contributes to decreased stability of the programme, increases training costs because of the need for continuous replacement and makes the programme difficult to manage. ${ }^{29}$

Overall, most CHWs had good perceptions regarding their training, teamwork and practice $(p=0.001)$. A significant correlation between work challenges and training was found ( $p=0.006)$. Challenges were experienced more by those trained compared with untrained CHWs and this could have been because of lack of the necessary equipment to provide services, among other challenges mentioned. These challenges present real concern for the PHC as well as WBOTs. All these need to be addressed in order to achieve health for all.

\section{Conclusion and recommendations}

In conclusion, the study findings showed that CHWs in Tshwane district had good perceptions regarding their training, teamwork and practice. The teams were able to provide an efficient healthcare service despite the challenges highlighted. For sustainability and continuous effectiveness of the programme, there is therefore a need for the Department of Health and other stakeholders to improve training, provide adequate material/equipment to offer good services, and consider incentivising the CHWs with a sustainable stipend, transport and safety.

\section{Limitations and strengths}

Convenience sampling allowed gathering of primary data from participants who were available on the day of data collection. However, since some of CHWs were off-duty on the scheduled day, this could have affected the sampling frame. The findings were based on self-reports and therefore prone to social desirability and information bias, although they are in line with the findings of previously published studies. The study was conducted across seven sub-districts of Tshwane, and oversampling reduced information bias and increased the power of the study.

Acknowledgement - The researchers would like to thank the Tshwane District Health Department for funding and everybody who assisted in the execution of this study: the field workers, data capturers, the statistician (Prof H. Schoeman), CHWs and their managers, Prof L.H. Mabuza and Prof I. Govender.

Disclosure statement - No potential conflict of interest was reported by the authors.

Author contributions - All authors were involved in the design and implementation of the study. The drafting of the manuscript was done by SLN. GAO reviewed the manuscript and all authors read and approved the final version.

\section{ORCID}

GA Ogunbanjo (D) http://orcid.org/0000-0002-8256-6571

\section{References}

1. International Labour Office. International standard classification of occupations (ISCO-08). Volume 1: Structure, group definitions and correspondence tables. Geneva: ILO; 2012:192. [cited 2017 November 7]. Available from: http://www.ilo.org/wcmsp5/groups/ public/---dgreports/---dcomm/---publ/documents/publication/wcms _172572.pdf

2. Harris M, Haines A. Brazil's family health programme. BMJ. 2010;341: c4945.

3. Sepulveda J, Bustreo F, Tapia R, et al. Improvement of child survival in Mexico: the diagonal approach. Lancet. 2006;368:2017-27.

4. World Health Organisation. Community health workers: What do we know about them? The state of the evidence on programmes, activities, costs and impact on health outcomes of using community health workers. WHO Evidence and Information for Policy Department of Human Resources for Health, Geneva. January 2007.

5. USAID. Community health worker programs: a review of the recent literature. New York City, LLC: USAID; 2010.

6. Haver J, Brieger W, Zoungrana J, et al. Experiences engaging community health workers to provide maternal and newborn health services: implementation of four programs. Int J Gynecol Obstet. 2015;130(Supplement 2):S32-9.

7. Roberton $T$, Applegate J, Lefevre $A E$, et al. Initial experiences and innovations in supervising community health workers for maternal newborn, and child health in Morogoro region, Tanzania. Hum Resour Health. 2015;13(1):19.

8. Patel AR, Nowalk MP. Expanding immunization coverage in rural India: a review of evidence for the role of community health workers. Vaccine. 2010;28(3):604-13.

9. Pillay $\mathrm{Y}$, Baron $\mathrm{P}$. The implementation of $\mathrm{PHC}$ re-engineering in South Africa: are we making progress. PHASA 29 Feb 2012 [cited 2017 July 13]. Available from: http://www.phasa.org.za/phcre-engineeringin south-africa-are-we-making-progress

10. Health Systems Trust. (2011) Community Health Workers: a brief description of the HST experience. [cited 2017 July 12]. Available from: http://www.hst.org.za/news/community-health-workers-briefdescription-hst-experience

11. Lehmann U, Sanders D. (2007) Community Health Workers: what do we know about them? [cited 2017 July 12]. Available from: http:// www.who.int/hrh/documents/community_health_workers.pdf

12. National Department of Health (NDOH). Republic of South Africa National health insurance in South Africa. Policy paper. Pretoria: Department of Health; [homepage on the internet] c2011. p. 59. [cited 2017 July 12]. Available from: http://www.health-e.org.za/ documents/2bcce61d2d1b8d972af41ab0e2c8a4ab.pdf

13. Department of Health, S. A. Provincial guidelines for the implementation of the three streams of PHC re-engineering. Republic of South Africa: DOH; 2011.

14. Bam N, Marcus T, Hugo J, et al. Conceptualizing Community Oriented Primary Care (COPC) - the Tshwane, South Africa, health post model. Afr J Prm Health Care Fam Med. 2013;5(1), Art. \#423, 3 pages. [cited 2017 July 12]. http://dx.doi.org/10.4102/phcfm.v5i1.423

15. Kinkel H, Marcus T, Memon S, et al. Community oriented primary care in Tshwane district, South Africa: assessing the first phase of implementation. Afr J Prm Health Care Fam Med, 2013 [cited 2017 
July 12]. Available from: http://www.phcfm.org/index.php/phcfm/ article/view/477/554

16. Komane L. Tshwane District WBOT presentation- Unicef. 9 November 2016 [cited 2018 October 6]. Available from: https://www.unicef.org/ southafrica/SAF_resource_kbsthroughwbot.pdf

17. Jinabhai CC, Marcus TC, Chaponda A. Rapid appraisal of ward-based outreach teams, 16 October 2015 Report. [cited 2018 October 6]. Available from: https://www.up.ac.za/media/shared/62/COPC/ .... ./wbotreport-epub-Ir-2.zp86437.pdf

18. Lehohla P. Comparison of the demographic profile of two cities Cape Town and Tshwane, 1997-2011. Statistics South Africa. Pretoria: Statistics South Africa; 2014.

19. Ogunmefun C, Rhulane M, Muzi M, et al. An audit of community health workers in the district of North West Province. HST, September 2011 [cited 2017 July 14]. Available from: http://www. hst.org,za

20. Padayachee $T$, Chetty N, Matse $M$, et al. Progress in the establishment of ward-based outreach teams. In: Padarath A, English R, editors. South African health review 2013/14. Durban: Health Systems Trust; 2014 [cited 2017 July 14]. Available from: http://www.hst.org.za/ publications/southafrican-health-review-2013/14.

21. Nxumalo N. Ward-based outreach community health worker outreach team: the success of sedibeng health posts. Policy Brief 2014 [cited 2017 July 14]. Available from: www.chp.ac.za

22. Kok MC, Kane SS, Ormel H, et al. How does context influence community health workers in low and middle-income countries? Evidence from literature. Health Res Policy Sys. 2015;13(1):1-14. [cited 2019 February 19]. Available from: https://doi.org/10.1186/s1296-015-001-3

23. Akintola O, Chikoko G. Factors influencing motivation and job satisfaction among supervisors of community health workers in marginalized communities in South Africa. Hum Resour Health. 2016;14:54. [cited 2018 April 27]. Available from: https://human-res ources-health.biomedcentral.com/articles/10 .../s12960-016-0151-6 (Accessed: 27/04/18)

24. Viswanathan K, Hansen PM, Rahman MH, et al. Can community health workers increase coverage of reproductive health service? J Epidemiol Community Health. 2012;66:894-900. [cited 2019 February 20]. Available from: http://dx.doi.org/10.1136/jech-200275. (Accessed 20/02/19).

25. Razee $H$, Whittaker $M$, Jayasuriya $R$, et al. Listening to the rural health workers in Papau New Guinea- the social factors that influence their motivation to work. Soc Sci Med. 2012;75(5):828-35. https://doi.org/ 10.1016/j.sosscimed.2012.04.013. [cited 2019 February 20]. Available from: https://www.sciencedirect.com/science/article/pii/S027795361 2003577?via\%3Dihub

26. Austin-Evelyn K, Rabkin M, Macheka T, et al. Community health worker perspectives on a new primary health care initiative in the Eastern Cape of SouthAfrica. PLoS One. 2017;12(3):e0173863. [cited 2018 April 27]. Available from: https://doi.org/10.1371/journal.pone. 0173863

27. Grant M, Wilford A, Haskins L, et al. Trust of community health workers influences the acceptance of community-based maternal and child health services. Afr J Prm Health Care Fam Med. 2017;9 (1), a1281. https://doi.org/10.4102/phcfm. v9i1.1281

28. Seutloali T, Napoles L, Bam N. Community health workers in Lesotho: experiences of health promotion activities. Afr J Prm Health Care Fam Med. 2018;10(1):a1558. [cited 2017 May 30]. Available from: https:// doi.org/10.4102/phcfm.v10i1.1558

29. Haines A, Sanders D, Lehmann U, et al. Achieving child survival goals: potential contribution of community health workers. Lancet 2007;369(9579):2121-31. [cited 2019 February 20]. Available from: https://doi.org/10.1016/S0140-6736(07)60325-0

Received: 12-06-2018 Accepted: 26-04-2019 